\title{
Intralesional Bleomycin injection in head and neck haemangioma and vascular malformation: A nonsurgical treatment
}

\author{
Regmi $D^{1}$, Bista $\mathrm{M}^{2}$, Shrestha $\mathrm{S}^{3}$, Chhetri $\mathrm{SS}^{4}$, Shrestha $\mathrm{D}^{5}$, Mahato $\mathrm{NB}^{6}$ \\ ${ }^{1}$ Deepak Regmi, Assistant Professor; ${ }^{2}$ Meera Bista, Associate Professor; ${ }^{3}$ Sangita Shrestha, Associate Professor; ${ }^{4}$ Sujan \\ Singh Chhetri, Assistant Professor; ${ }^{5}$ Diva Shrestha, Lecturer; ${ }^{6}$ Nain Bahadur Mahato, Lecturer; Department of ENT-HNS, \\ Kathmandu Medical College Teaching Hospital, Kathmandu, Nepal.
}

\begin{abstract}
Background: Successful management of vascular anomaly of head and neck region are often challenging. As the surgical modality carries high complications and bad aesthetic outcome, the treatment paradigm for these lesions has been shifting towards the non-invasive one. Because of its high sclerosing effect on vascular endothelium, low cost and easy availability intralesional Bleomycin injection can be an alternative.

Objective: To determine the efficacy and safety of intralesional Bleomycin sclerotherapy for head and neck haemangioma and slow flow vascular malformation.

Methods: Thirty-six patients (12 males and 24 females) with head and neck haemangioma and slow flow vascular malformations were treated with intralesional Bleomycin injection in the dose of $0.5 \mathrm{mg} / \mathrm{kg} / \mathrm{dose}$ (not exceeding $15 \mathrm{mg} /$ dose) in a medical college of Nepal. The repeat injection was offered every three weeks if needed. The size of the lesion was measured and serial photographs were taken. Complications were also recorded.

Results: Ten patients (28\%) had complete resolution (cured), 19 patients (53\%) had marked improvement five (14\%) had mild improvement and two (6\%) had no response. Minor complications like fever and transient rise in temperature were seen in eight patients (22\%). Hyperpigmentation of the overlying skin were observed in four(11\%). None of the patients developed haematological toxic side effects or pulmonary fibrosis during the follow up.

Conclusion: Intralesional Bleomycin injection is simple, safe, effective and non-invasive modality of the treatment for head and neck haemangioma and slow flow vascular malformation.
\end{abstract}

Key words: Bleomycin, Head and neck, Haemangioma, Intralesional, Vascular malformation

\section{INTRODUCTION}

Vascion ascular anomalies are among the most common congenital and neonatal abnormalities ${ }^{1}$. Head and neck is the most common site of occurrence of these lesions (60\%) followed by the trunk (25\%) and the extremities $(15 \%)^{2}$. These pathological conditions were commonly termed haemangioma in the past. Mulliken and Glowacki ${ }^{3}$ in 1982 gave a clear classification of these pathological conditions on the basis of physical findings, clinical behaviour and cellular kinetics. According to them, there are two types of vascular lesions: haemangiomas and vascular malformations. Haemangiomas are not

Address for correspondence

Dr. Deepak Regmi

Assistant Professor, Department of ENT-HNS

Kathmandu Medical College Teaching Hospital

Sinamangal, Kathmandu, Nepal.

E-mail: drdeepakregmi@hotmail.com present at birth and mostly manifest during the first month of life whereas vascular malformations are always present at birth. Haemangiomas show rapid proliferation during first two years of life then regress slowly whereas vascular malformations grow proportionally in size with the growth of the body and do not regress spontaneously. Waner and Suen ${ }^{4}$ later classified vascular malformations into slow flow (capillary, lymphatic and venous) and fast flow (arterial, arterio-venous fistula and arteriovenous malformation). Mathuret et.al ${ }^{5}$ refer the term 'haemodynamically less active' for the 'low flow' lesions. Available treatment modalities for vascular malformations are LASER, sclerotherapy, embolization, electrochemical therapy, alcoholic solution of Zein (Ethibloc), surgery or combination of these. Surgical excision is the favoured modality of treatment for vascular malformations in head and neck region. But the vicinity of complex neurovascular structure of this region 
may sometimes be a great challenge for a head and neck surgeon when they envelop the vital structures. Moreover, it may get complicated by wound infection or bad scar. So, percutaneous sclerotherapy was developed as a less invasive modality for the treatment of these lesions using Bleomycin, ethibloc, OK 432, etc. for haemangioma or slow flow vascular malformations. We chose percutaneous Bleomycin sclerotherapy because of its low cost, easy availability, effectiveness and safety ${ }^{6}$.

\section{METHODS}

With Institutional Review Committee approval, this prospective study was carried out in the Department of ENT-HNS in Kathmandu Medical College Teaching Hospital (Kathmandu, Nepal) from October 2014 to March 2017. Thirty-six patients of all the age and sex presenting with either haemangioma or slow flow vascular malformation and giving an informed consent for intralesional Bleomycin injection (IBI) were enrolled in the study.

Clinical data including age, sex, weight, location of the lesion, size (length and breadth), follow up period, number of injections, total Bleomycin dose and complications if any, were recorded in a predesigned proforma. The response was recorded by serial photography and measurement before, during and after completion of the treatment.

Diagnosis was made on the basis of history, clinical examination and Doppler ultrasound. Fine needle aspiration cytology and CT scan was required only in a few cases. Size measurement was done on the basis of clinical examination and/or ultrasound in every follow up. Complete blood count, chest X-ray, and renal function tests were also done before IBI in due course of treatment.

The procedure was always performed in the operation theatre in a day case basis without anaesthesia. The dose of the Bleomycin administered was $0.5 \mathrm{mg} / \mathrm{kg}$ body weight and varied according to the size of the lesion. A single dose of $15 \mathrm{mg}$ per session and total dose of $5 \mathrm{mg} / \mathrm{kg}$ was never exceeded ${ }^{7}$. Single vial of aqueous Bleomycin (15 mg) was diluted in $5 \mathrm{ml}$ of normal saline. The first author injected the calculated dose with 23-gauge needle through normal skin, if possible, and advanced to the haemangioma or vascular malformation at one to four sites in subdermal plane as suggested by Mathuret et. $\mathrm{al}^{5}$. Small volume was administered in superficial lesions for fear of ulcerations. Local pressure was applied for 5 to 10 minutes following injection. Patients were discharged by evening with mild analgesics if required. Follow up was done every 3 weeks and repeat injection was offered depending upon the clinical response. The clinical response to treatment (size reduction) was assessed by all the authors on the basis of measurements, photographs and sonographic reports and it was graded as proposed by Hassanet al $^{6}$. (Table 1)

\section{Table 1: Grading of clinical response to IBI (Hassan et al) ${ }^{6}$}

\begin{tabular}{|c|c|c|}
\hline S.N. & Response & Description \\
\hline 1 & No Response & $\begin{array}{l}\text { No change in the size or continued } \\
\text { to enlarge }\end{array}$ \\
\hline 2 & $\begin{array}{l}\text { Mild } \\
\text { improvement }\end{array}$ & $\begin{array}{l}\text { The lesions decreased in size, but } \\
\text { less than } 50 \% \text { with improvement } \\
\text { in appearance }\end{array}$ \\
\hline 3 & $\begin{array}{l}\text { Marked } \\
\text { improvement }\end{array}$ & $\begin{array}{l}\text { The lesions decreased in size more } \\
\text { than } 51 \% \text {, but less than } 100 \% \\
\text { with remarkable improvement } \\
\text { appearance }\end{array}$ \\
\hline 4 & Cured & $\begin{array}{l}\text { The lesions disappeared } \\
\text { completely without recurrence at } \\
\text { least } 6 \text { months after treatment }\end{array}$ \\
\hline
\end{tabular}

The main goal of the treatment was the size reduction. Sclerotherapy sessions were repeated until the patient was satisfied with the outcome or tolerate residual symptoms. The procedure was abandoned when the clinician felt there was no role of further treatment.

\section{RESULTS}

There were 24 females and 12 males. Age ranged from five years to 54 years with a mean age of 25 years. Most of the cases were slow flow vascular malformations (86\%) and only five cases of haemangioma (14\%) were managed with IBI during the study period (30 months). Duration of the follow up ranged from four to 34 months (mean=18 months). Commonest site of these lesions were oral cavity and oropharynx in 12 (33.3\%) followed by neck in five (13\%), cheek in six (16\%), lip in five (13\%), parotid in four (11\%), ear in two (5\%) and nose in two (5\%). Number of injection ranged from two to seven $($ mean $=5)$.

Ten patients (28\%) had complete resolution (cured), 19 had marked improvement (53\%), five had mild improvement (14\%) and two had no response (6\%)

Complication like fever and transient rise in temperature were encountered in $22 \%$ patients. Hyperpigmentation of the overlying skin was observed in $11 \%$. None of the patient developed haematological toxic side effects or pulmonary fibrosis during the follow up. 


\section{DISCUSSION}

Percutaneous sclerotherapy is an injection of sclerosing agent directly through the skin into the lesion for venous or lymphatic malformation. Various sclerosants have been used in the past for haemangioma and vascular malformation. A plethora of literature has been emerging with regards to the different techniques and injectable sclerosants. Ethanol is the workhorse sclerosant with the efficacy rate ranging from $75 \%$ to $95 \%{ }^{8,9}$. But it inherits high risk of nerve injury, skin necrosis, thrombophlebitis and cardiovascular collapse when it enters into the circulation.

OK432 (a low virulence strains if Streptococcus pyogenesis cultured with penicillin-G) is another potent biological response modifier. It has been used extensively in lymphangioma. Fever and swelling are the common adverse effects. The availability and cost factor limit its use in our setup.

Alcoholic solution of Zein (Ethibloc) is another sclerosing agent for the treatment of venous malformation. Its adverse effects include pain, swelling, ecchymosis, fistulisation to the skin and phlebitis.

Injection Bleomycin was selected as a sclerosant in our study because of its low cost and easy availability. It is a mixture of cytotoxic glycoprotein antibiotics isolated from strains of Streptomyces verticillus. It was discovered by Umezawa ${ }^{10}$ as antitumor agent in 1966, mechanistically it acts through inhibition of DNA synthesis. Later on, it was found to have sclerosing effect on endothelial cell during its treatment of malignant pleural effusion. Yura et al ${ }^{11}$ in 1977 first studied its intralesional sclerosing effect in macrocystic lymphangioma and achieved good result in all eight cases. Sarihanet al ${ }^{12}$ was the first to use it in cutaneous haemangioma in 1997.

Most of the cases in our series were adults with vascular malformations $(n=31)$. Only five cases of haemangioma were eligible for IBI. Lower incidence of haemangiomas in our study might be due to lower number of paediatric patients visiting our outpatient department as they might have consulted paediatricians or the plastic surgeons. The female to male ratio was 2:1 which is in agreement with other studies ${ }^{6,13}$. Lip was the commonest site for haemangioma, whereas oral cavity and oropharynx were the commonest site for slow flow vascular malformations. The number of injection required ranged from 2 to 7 (mean $=5)$ which was similar to Pienaaret et.al ${ }^{13}$ and Hassanet $\mathrm{al}^{6}$. Percutaneous intralesional Bleomycin injection causes destruction of the vascular endothelial cells, hence produce sclerosing effect. Duration of three weeks was found to be consistent with the expected changes in the haemangioma and slow flow vascular malformation. That was the reason to repeat injection every three weeks in this study.

More than 50\% improvement was observed in $81 \%$ patients among them 28\% were cured. Almost 20\% patients showed mild or no response and surgery, as alternative treatment option, was sought for them. Results of this series were comparable with other reports ${ }^{6,13,14,15}$ and it was similar or even better compared to surgical modality ${ }^{16}$. Complications like nerve palsy and bad scar were, thus, avoided.

Very few minor complications encountered in this study were transient rise in temperature, fever and hyperpigmentation of overlying skin. The most feared complication of intralesional Bleomycin is pulmonary fibrosis which is major complication seen among the cancer patients treated with systemic route, but it is dose related. The recommended dose for IBI is $1 \mathrm{mg} / \mathrm{kg} /$ dose or summated dose should not exceed $5 \mathrm{mg} / \mathrm{kg}$. The dose we employed in this study was $0.5 \mathrm{mg} / \mathrm{kg} /$ dose, which was much lower to cause pulmonary complications. To date, no cases of pulmonary fibrosis have been reported in the literature following its use as sclerotherapy. This is likely because it does not go into the circulation as opposed to patients treated systemically. Lonescu et al ${ }^{17}$ did a study in four paediatric patients who were treated with intralesional Bleomycin for haemangioma. They did not find detectable bleomycin in blood samples taken at 10 minutes and 24 hours following sclerotherapy. Our policy was not to exceed the Bleomycin $15 \mathrm{mg}$ (per session) and $250 \mathrm{mg}$ (cumulative) which was far below the systemic dose of $450 \mathrm{mg}$ recognized in cancer literature to increase the risk of pulmonary fibrosis ${ }^{18}$. $\mathrm{IBI}$ is the modality of choice for all head and neck haemangioma and slow flow vascular malformation in our centre before considering surgical excision.

\section{CONCLUSION}

Intralesional Bleomycin injection (IBI) is simple, safe, effective and non-invasive modality of the treatment for head and neck haemangioma and slow flow vascular malformation. This modality of treatment has to be considered before surgical excision in the aesthetic and functional point of view. 


\section{REFERENCES}

1. Garzon MC, Enjolras O, Frieden IJ.Vascular tumors and vascular malformations: Evidence for an association. J Am AcadDermatol. 2000;42:275-9.

2. Finn MC, Glowacki J, Mulliken JB. Congenital vascular lesions: clinical application of a new classification. J Pediatr Surg. 1983;18:894-900.

3. Mulliken JB, Glowacki J.Hemangiomas and vascular malformations of infants and children: A classification based on endothelial characteristics. PlastReconstr Surg.1982; 69:412-22.

4. Waner M, Suen JY, editors. Hemangiomas and vascular malformations of the head and neck. New York: Wiley-Liss; 1999 Mar 25.

5. Mathur NN, Rana I, Bothra R, Dhawan R, Kathuria G, Pradhan T. Bleomycinsclerotherapy in congenital lymphatic and vascular malformations of head and neck. International journal of pediatric otorhinolaryngology. 2005 Jan 31;69(1):7580.

6. Hassan Y, Osman AK, Altyeb A. Noninvasive management of hemangioma and vascular malformation using intralesionalbleomycin injection. Annals of plastic surgery. 2013 Jan 1;70(1):70-3.

7. Kullendorff CM. Efficacy of bleomycin treatment for symptomatic hemangiomas in children. Pediatric surgery international. 1997 Jul 1;12(7):526-8.

8. Legiehn GM, Heran MK. Venous malformations: classification, development, diagnosis, and interventional radiologic management. RadiolClin N Am. 2008;46:545-97.

9. Berenguer B, Burrows PE, Zurakowski D, Mulliken JB. Sclerotherapy of craniofacial venous malformations: complications and results. PlastReconstr Surg. 1999;104:1-11.

10. Umezawa $\mathrm{H}$. Recent studies on biochemistry and action of bleomycin. Bleomycin, current status and new developments. NY: Academic. 1978;15-20.

11. Yura J, Hashimoto T, Takahashi L, et al. Bleomycin treatment for cystic hygroma in children. Nihon GekaHokan. 1977;46:607-14.

12. Sarihan H, Mocan H, Yildiz K, Abes M, Akyazici R. A new treatment with bleomycin for complicated cutaneous hemangioma in children. European journal of pediatric surgery. 1997 Jun;7(03):158-62.

13. Pienaar C, Graham R, Geldenhuys S, Hudson DA. Intralesionalbleomycin for the treatment of hemangiomas. Plastic and reconstructive surgery. 2006 Jan 1;117(1):221-6.

14. Zhao JH, Zhang WF, Zhao YF. Sclerotherapy of oral and facial venous malformations with use of pingyangmycin and/or sodium morrhuate. Int J Oral Maxillofac Surg. 2004;33:463-6.

15. Achauer BM, Chang CJ, Vander Kam VM. Management of hemangioma of infancy: review of 245 patients. Plastic and reconstructive surgery. 1997 May 1;99(5):1301-8.

16. Kane WJ, Morris S, Jackson IT, Woods JE. Significant hemangiomas and vascular malformations of the head and neck: clinical management and treatment outcomes. Annals of plastic surgery. 1995 Aug 1;35(2):133-43.

17. Lonescu G, Mabeta P, Dippenaar N, Muir T, Fourie $P$, Shelver $G$. Bleomycin plasma spill-over levels in paediatric patients undergoing intralesional injection for the treatment of haemangiomas. SAMJ. 2008 Jul;98(7):538-40.

18. Blum R. A clinical review of bleomycin: a new antineoplastic agent. Cancer. 1973;31:903-14. 